\title{
Atmospheric remote sensing constraints on direct sea-air methane flux from the 22/4b North Sea massive blowout bubble plume
}

\author{
Konstantin Gerilowski ${ }^{a, *}$, Thomas Krings a , Jörg Hartmann ${ }^{b}$, Michael Buchwitz ${ }^{a}$, \\ Torsten Sachs ${ }^{c}$, Jörg Erzinger ${ }^{c}$, John P. Burrows ${ }^{\mathrm{a}}$, Heinrich Bovensmann ${ }^{\mathrm{a}}$ \\ a University of Bremen, Institute of Environmental Physics (IUP), P.O. Box 330440, 28334 Bremen, Germany \\ ${ }^{\mathrm{b}}$ Alfred Wegener Institute for Polar and Marine Research (AWI), Am Handelshafen 12, 27570 Bremerhaven, Germany \\ ${ }^{\mathrm{C}}$ Helmholtz Centre Potsdam - GFZ German Research Centre for Geosciences, Telegrafenberg, 14473 Potsdam, Germany
}

\section{A R T I C L E I N F O}

\section{Article history:}

Received 23 December 2013

Received in revised form 23 January 2015

Accepted 10 July 2015

Available online 17 July 2015

\section{Keywords:}

Remote sensing

Glint

Aircraft

Methane

Blowout

Emission estimate

\begin{abstract}
A B S T R A C T
A new airborne remote sensing approach to estimate an upper limit of the direct sea-air methane emission flux was applied over the $22 / 4 \mathrm{~b}$ blowout site located at N57.92 ${ }^{\circ}$, E1.63 ${ }^{\circ}$ in the North Sea. Passive remote sensing data using sunglint/sunglitter geometry were collected during instrumental tests with the Methane Airborne MAPper - MAMAP - instrument installed aboard the Alfred Wegener Institute (AWI) Polar-5 aircraft on 3. June 2011. MAMAP is a passive short wave infrared (SWIR) remote sensing spectrometer for airborne measurements and retrieval of the atmospheric column-averaged dry air mole fractions of methane $\left(\mathrm{XCH}_{4}\right)$ and carbon dioxide $\left(\mathrm{XCO}_{2}\right)$. In addition to MAMAP a fast $\mathrm{CH}_{4}$ in-situ analyzer (Los-Gatos Research Inc. RMT-200), two 5-hole turbulence probes and the Polar-5 basic sensor suite comprising different temperature, pressure, humidity and camera sensors were installed aboard the aircraft. The collected MAMAP remote sensing data acquired in the vicinity of the 22/4b blowout site showed no detectable increase in the derived $\mathrm{XCH}_{4}$ (with respect to the atmospheric background). Based on the absence of a detectable $\mathrm{XCH}_{4}$ column increase, an approximate top-down upper-limit for the direct atmospheric 22/4b blowout $\mathrm{CH}_{4}$ emissions from the main bubble plume of less than $10 \mathrm{ktCH} / \mathrm{yr}$ has been derived. The constraint has been determined by comparing $\mathrm{XCH}_{4}$ information derived by the remote sensing measurements with results obtained from a Gaussian plume forward model simulation taking into account the actual flight track, the instrument sensitivity and measurement geometry, as well as the prevailing atmospheric conditions.
\end{abstract}

(C) 2015 Elsevier Ltd. All rights reserved.

\section{Introduction}

In 1990, Mobil North Sea Ltd. (MNSL) encountered shallow gas at $360 \mathrm{~m}$ below seabed, while drilling the exploration well UK22/4b-4, located $\sim 200 \mathrm{~km}$ east of the Scottish mainland at $\mathrm{N} 57.92^{\circ}, \mathrm{E} 1.63^{\circ}$. The well blew out, creating a massive bubble plume that rapidly decreased after several days. After monitoring of the site by ship and remotely operated vehicle (ROV) surveys from 1990 to 1998, the UK Department of Trade and Industry (DTI) determined that there was no evidence of environmental harm and risk to health and safety in 2000 and thus decided that further monitoring was not required (see also Leifer and Judd, this issue). Nevertheless, a ship survey in 2005 showed strong emissions

\footnotetext{
* Corresponding author.

E-mail address: gerilows@iup.physik.uni-bremen.de (K. Gerilowski).
}

continuing with a visible bubble plume diameter of approximately $30 \mathrm{~m}$ at the sea surface (Schneider von Deimling et al., 2007). In 2010, the UK Department of Environment and Climate Change (DECC) initiated a study to assess the current status of the $22 / 4 \mathrm{~b}$ site and to better understand the nature and fate of the gas discharge (Leifer and Judd, this issue).

Up to now there are only a few methods available, which enable the emissions, i.e. surface fluxes to the atmosphere, from localized marine sources (point sources) to be estimated or constrained. These methods typically incorporate ship-based or airborne in-situ measurements in combination with inverse atmospheric modeling. Such an approach was applied for instance to assess the direct atmospheric emissions during the Elgin blowout accident in the North-Sea in 2012 (Mobbs et al., 2012). A drawback of such airborne methods is that they often require low level flight operation e.g. below $500 \mathrm{ft}(\sim 150 \mathrm{~m})$ over ground (depending on boundary layer thickness). Regulations such as the minimum safe altitude, or 
exclusion zones as established around the Elgin rig in 2012 (Mobbs et al., 2012) could restrict the range of the required flight plans and patterns.

Passive remote sensing technologies offer the potential to overcome these drawbacks, as they sample the atmospheric concentrations around the source remotely from above the boundary layer. However, remote sensing instruments using short wave infrared (SWIR) radiation suffer from the weak reflectivity of water in that spectral region, when measuring in nadir or off nadir directions. To overcome this drawback the use of sunglint has been proposed by Larsen and Stamnes (2006) for methane anomaly detection from space by means of passive remote sensing in the SWIR spectral range. Such approaches have demonstrated the successful detection of methane anomalies over natural marine seepage by using airborne hyper spectral imaging (HSI) instruments operating the SWIR (Roberts et al., 2010; Bradley et al., 2011; Thorpe et al., 2014, and references therein). Recently, successful tests of airborne methane anomaly detection over marine sources have also been demonstrated from retrieved data collected by airborne hyper spectral imaging instruments in the thermal infrared spectral range (Tratt et al., 2014).

Another approach for the retrieval of accurate greenhouse gas (GHG) information is the use of medium and high spectral resolution absorption spectroscopy (i.e. the line shape is such that the FWHM is better than approximately $1 \mathrm{~nm}$ ) in the SWIR. In contrast to the low spectral resolution spectroscopy, remote sensing with medium and high spectral resolution has the ability to achieve higher accuracy and precision as a result of the much lower sensitivity to potentially spectrally interfering surface spectral reflection features and the lower sensitivity to other gaseous absorbers in the same spectral range. Medium and high spectral resolution spectroscopy has been widely used for accurate retrieval of greenhouse gases in nadir geometry from aircraft (Krings et al., 2011; Gerilowski et al., 2011), and from space (e.g. Schneising et al., 2014, and references therein). Recently, the use of sun glint has been demonstrated for the retrieval of $\mathrm{CH}_{4}$ with high accuracy and precision from space (Butz et al., 2013).

To demonstrate the ability of accurate sun glint retrieval with medium resolution spectroscopy from aircraft, a team from IUP, GFZ, and AWI equipped the AWI Polar-5 BT-57 aircraft (a Basler modified DC-3T) with a medium spectral resolution spectrometer, to perform a test measurement over the 22/4b blowout site within the framework of a joint campaign called AIRMETH. The AIRMETH payload for that flight consisted primarily of the Methane Airborne MAPper - MAMAP, a passive near infrared (NIR) and SWIR remote sensing instrument (Gerilowski et al., 2011) to determine column-averaged dry air mole fractions of the greenhouse gases methane, $\mathrm{CH}_{4}$ (denoted as $\mathrm{XCH}_{4}$ ) and carbon dioxide, $\mathrm{CO}_{2}$ (denoted as $\mathrm{XCO}_{2}$ ) (Krings et al., 2011, 2013), a fast $\mathrm{CH}_{4}$ insitu analyzer (Los-Gatos Research Inc. RMT-200), two turbulence probes (an AIMMS-20 and the custom developed AWI- nose-boom turbulence probe, Cremer, 2008), the Polar-5 basic sensor suite comprising different temperature, pressure, humidity and camera sensors, as well as a data acquisition and assimilation system (Optimare MEDUSA-P).

On 3. June 2011 several flights over the 22/4b blowout site were performed and remote sensing and in-situ data were collected. Based on the MAMAP remote sensing data, acquired using sunglint/sunglitter geometry, an approximate top-down constraint for the direct atmospheric $22 / 4 \mathrm{~b}$ blowout $\mathrm{CH}_{4}$ emissions from the main bubble plume area has been derived. The constraint has been determined by the comparison of $\mathrm{XCH}_{4}$ predicted differences calculated by an Observation System Simulation Experiment (OSSE) incorporating different Gaussian plume forward model simulations, and taking into account the instrument noise and sensitivity, the actual flight track and the prevailing atmospheric conditions. Results from the OSSE have been compared to the $\mathrm{XCH}_{4}$ retrieved from the MAMAP measured spectra, and an upper limit of the direct 22/4b blowout surface flux caused by ebullition could be derived. OSSE simulations for measurements with the same instrument configuration performed one day later (4. June, 2011), but in nadir geometry, over a terrestrial point source with known emission strength, are presented for comparison and justification of the used approach.

This manuscript is organized as follows: Section 2 describes the used instrumentation and briefly explains the remote sensing retrieval algorithm as well as the methodology applied for emission simulation. Section 3 presents the successfully accomplished measurements and summarizes the results. Section 4 describes the simulations used to determine the upper limit or constraint for the direct surface flux form the 22/4b blowout site. Section 5 summarizes the results and presents the conclusions.

\section{Instrumentation and methodology}

\subsection{Instrumentation}

\subsubsection{Remote sensing instrumentation for atmospheric greenhouse gas measurements}

The remote sensing instrument for GHG measurements installed on the Polar-5 aircraft in addition to its basic sensor suite, is MAMAP, a passive nadir looking spectrometer system for retrieval of methane $\left(\mathrm{CH}_{4}\right)$ and carbon dioxide $\left(\mathrm{CO}_{2}\right)$ vertical columns and column-averaged mole fractions, $\mathrm{XCH}_{4}$ and $\mathrm{XCO}_{2}$ (Gerilowski et al., 2011). This instrument was developed by the Institute of Environmental Physics (IUP), University of Bremen, Germany in cooperation with the Helmholtz Centre, Potsdam German Research Centre for Geosciences (GFZ). MAMAP measures back-scattered and surface-reflected solar radiation (see Fig. 1) in the Short Wave Infrared (SWIR) and Near-Infrared (NIR) spectral range at moderate spectral resolution. The NIR channel at around $0.76 \mu \mathrm{m}$ measures the atmospheric $\mathrm{O}_{2}$-A-band absorption with a resolution of $\sim 0.46 \mathrm{~nm}$ full width at half maximum (FWHM). The SWIR channel yields measurements of absorption bands of $\mathrm{CH}_{4}$ and $\mathrm{CO}_{2}$ in the spectral range from $\sim 1.59$ to $1.69 \mu \mathrm{m}$ at a spectral resolution of $\sim 0.86 \mathrm{~nm}$ FWHM. Information from these bands is used for the retrieval of the column-averaged dry air mole fractions of $\mathrm{CH}_{4}$ and $\mathrm{CO}_{2}$ (denoted as $\mathrm{XCH}_{4}$ and $\mathrm{XCO}_{2}$, see also Gerilowski et al., 2011; Krings et al., 2011). These data can be used for top-down estimates of atmospheric surface fluxes of local sources via inverse modeling (Krings et al., 2011, 2013). In addition to the MAMAP instrument, also a push-broom imaging DOAS spectrometer instrument for remote sensing measurements of nitrogen dioxide $\left(\mathrm{NO}_{2}\right)$ was installed on the aircraft, as described in Schönhardt et al. (2014).

As a result of the weak reflectivity of water in the relevant SWIR spectral range, signal to noise ratios (SNR) over water are small and typically not sufficient for accurate retrieval of $\mathrm{XCH}_{4}$ or $\mathrm{XCO}_{2}$. To improve the SNR over water, the MAMAP instrument was modified for sunglint/sunglitter operation in 2011 by introducing a fiber coupled gimbal telescope mounted on a ZEISS SM-2000 gyrostabilized platform. This gimbal can be manually pre-adjusted on demand to a fixed position for nadir or sunglint operation. After the pre-adjustment, the position is stabilized and tracked automatically by a SM2000 gyro-stabilized platform. Inclination and heading of the optical head was recorded by a Microstrain 3DM-GX1 and a 3DM-GX3 attitude heading reference system (AHRS). The described modification has been used to collect data in sunglint geometry over the $22 / 4 \mathrm{~b}$ blowout site. 

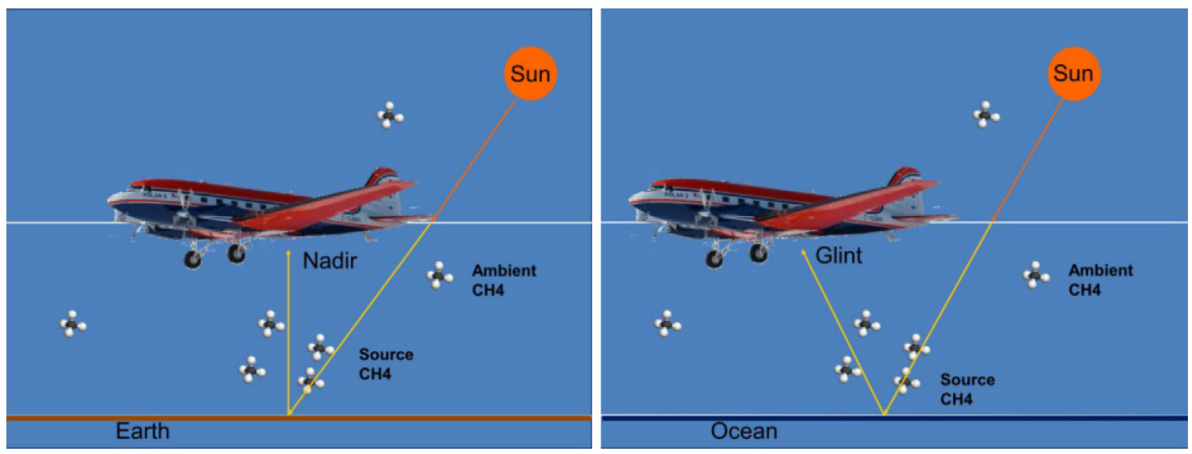

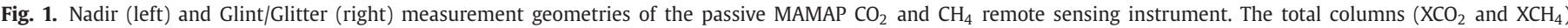

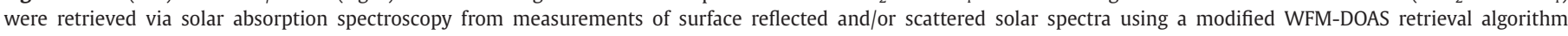
(Krings et al., 2011). Light passes twice through the atmosphere below the aircraft.

\subsubsection{Fast in-situ $\mathrm{CH}_{4}$ analyzer}

The second scientific instrument installed on the aircraft in addition for the AIRMETH campaign was a continuous wave Integrated Cavity Output Spectroscopy (cw-ICOS, O’Keefe, 1999) LosGatos Research Inc. RMT-200 fast $\mathrm{CH}_{4}$ in-situ analyzer operated by the Alfred Wegener Institute (AWI) for Polar and Marine Research. The analyzer was equipped with an external pump to deliver fast in-situ $\mathrm{CH}_{4}$ measurements with a temporal resolution of $10 \mathrm{~Hz}$. The raw measurements of the RMT were corrected for spectroscopic effects of water vapor by a method described in Peltola et al. (2013) using humidity measurements of a VAISALA HMT333 sensor. The HMT333 humidity measurements were also used for the conversion from wet mole to dry air mole fraction. In addition, a flask sampler permitted acquisition of single gas samples for further laboratory analysis and calibration of the system.

\subsubsection{Turbulence probes and Polar-5 basic instrumentation}

In addition to the remote sensing and in-situ sensors for detection of $\mathrm{CH}_{4}$, the AWI-Polar 5 aircraft was equipped for the AIRMETH campaign with 2 different turbulence probes as well as the Polar-5 basic sensor suite to deliver horizontal and vertical wind as well as pressure, humidity, and temperature information. The nose-boom is equipped with a 5-hole probe and Rosemount pressure transducers. Temperature is measured by a Pt100 in Rosemount housings. For humidity a capacity type sensor (HMT333) was also mounted in a Rosemount housing at the nose boom. Additionally a CR2 dew point mirror provided accurate absolute humidity information. The aircraft motion is recorded by a Honeywell Lasernav and several GPS systems. Data acquisition and assimilation was performed by the Optimare MEDUSA-P system. These data can be used for analysis of the atmospheric conditions, i.e. atmospheric stratification, wind speed and direction as well as boundary layer height and atmospheric stability. The second probe, which was mounted on the wing and belongs to the basic sensor suite, is a commercial Aventech Inc. AIMMS-20 turbulence probe with a horizontal wind precision of $0.5 \mathrm{~m} / \mathrm{s}$ and a vertical wind precision of $0.75 \mathrm{~m} / \mathrm{s}$ (see http://www.aventech.com/ products/aimms20.php). This probe can operate at data acquisition rates of up to $40 \mathrm{~Hz}$. Data from this probe is used for comparison to surface wind information obtained from the nearest weather stations, which is needed for the Gaussian plume forward model simulations. Data from the first AWI nose-boom turbulence probe was not utilized for the wind estimates due to problems with one of the pressure transducers during the $22 / 4 \mathrm{~b}$ overflights.

\subsection{Data retrieval and flux modeling}

\subsubsection{WFM-DOAS data retrieval algorithm}

To retrieve the column averaged dry air mole fractions $\left(\mathrm{XCH}_{4}\right)$ from the measured spectra the Weighting Function Modified Dif- ferential Optical Absorption Spectroscopy (WFM-DOAS) algorithm has been used. A detailed description and application examples are given in Krings et al. (2011, 2013) and are therefore only shortly summarized here. The retrieval fits a linearized radiative transfer model (RTM) to the acquired data. As radiative transfer model SCIATRAN (Rozanov et al., 2013) has been used. SCIATRAN also provides the radiance derivatives or weighting functions for all relevant fit parameters, most notably for $\mathrm{CH}_{4}$ and $\mathrm{CO}_{2}$ but also for water vapor absorption. Low frequency radiance variations, e.g. due to surface spectral reflection/albedo variations, are taken into account by an additional low-order polynomial.

\subsubsection{Gaussian plume forward model simulation and OSSE}

To estimate the $\mathrm{CH}_{4}$ emission rates (and/or to determine an upper limit) from the $\mathrm{XCH}_{4}$ observations at the 22/4b target, vertically integrated high spatially resolved (i.e. $10 \mathrm{~m} \times 10 \mathrm{~m}$ ) Gaussian plume forward model simulations for different flux rates and atmospheric conditions have been conducted (see Krings et al., 2011, and references therein):

$V(x, y)=\frac{F}{\sqrt{2 \pi} \sigma_{y}(x) u} e^{-\frac{1}{2}\left(\frac{y}{\sigma_{y}(x)}\right)^{2}}$

here $V(\mathrm{x}, \mathrm{y})$ denotes the simulated vertical column of $\mathrm{CH}_{4}\left(\mathrm{XCH}_{4}\right)$ distribution depending on horizontal location over ground, $\sigma_{\mathrm{y}}$ denotes the horizontal dispersion coefficient, $u$ denotes the mean wind speed used for the simulation and $F$ the emission rate. The parameter $x$ describes the lateral axis (in meter) in wind direction and $y$ the lateral axis (in meter) in across wind direction. The stability parameter $\sigma_{\mathrm{y}}$ (in meter) can be calculated by $\sigma_{\mathrm{y}}=a \cdot(\mathrm{x} / 1000)^{\mathrm{c}}$ with the empirical unit less constants $c$ $(c=0.894)$ and the unit less stability type $a$ with values between $a=213$ and $a=34$ according to the stability classes "A" to "F" (Martin, 1976).

The stability class (over water) can be typically estimated directly from aircraft profile wind and temperature measurements, as well as from ground based measurements and the knowledge of the sea surface temperature according to Hasse and Weber (1985). Thereafter, the simulated data were re-gridded quadratically to $50 \mathrm{~m} \times 50 \mathrm{~m}$ to reflect the approximate MAMAP spatial resolution of $\sim 50 \mathrm{~m} \times 33 \mathrm{~m}$ for that flight (along $\times$ across-track, dependent on aircraft altitude, exposure time and flight speed) and taking the real flight track and approximate sample position into account. To better compare to the real measurements, typical instrument measurement noise (see also Gerilowski et al., 2011; Krings et al., 2013) was added to the model data. Model data obtained from such an approach (see Fig. 2), which is also known as an 


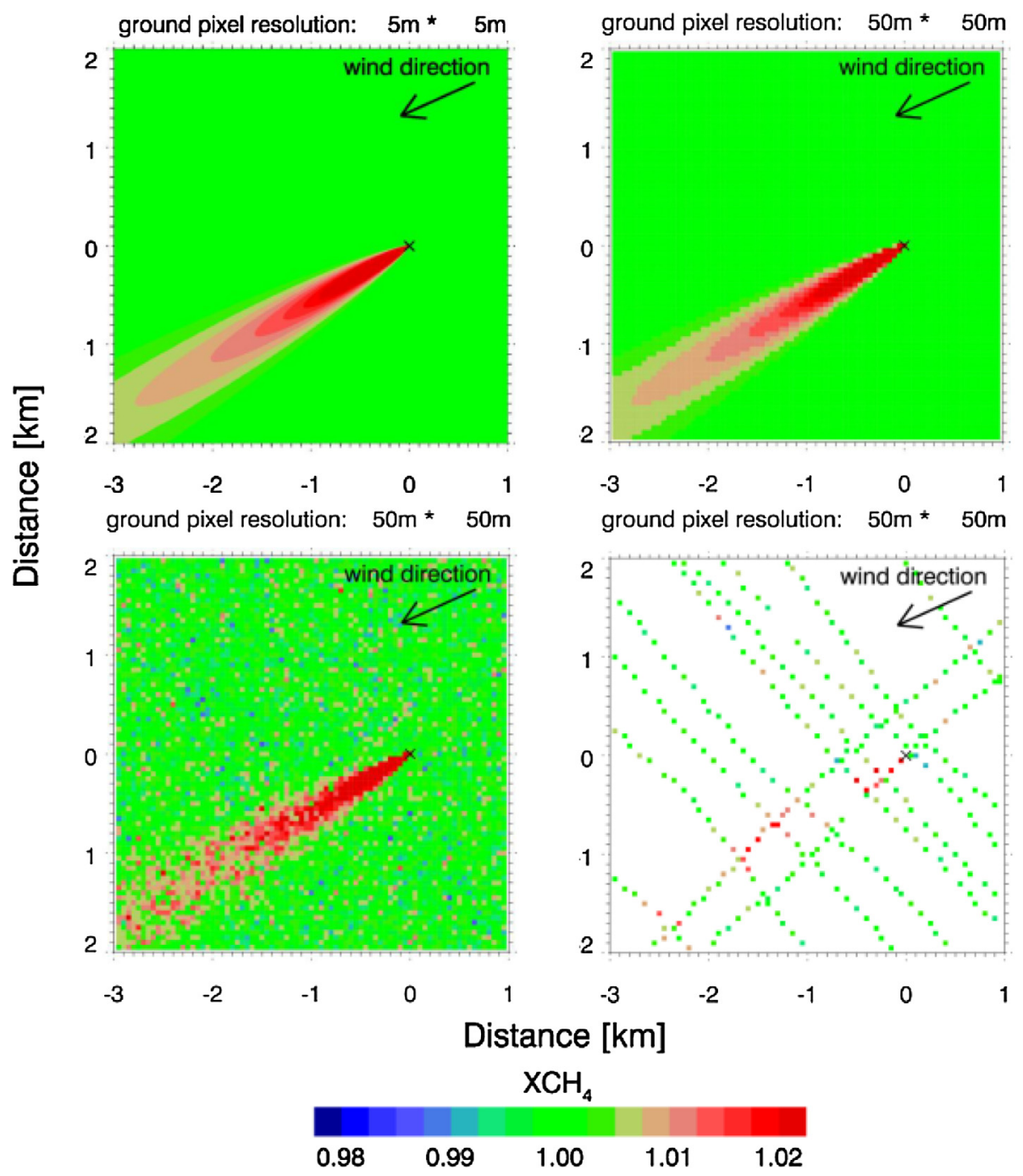

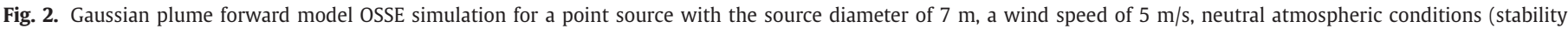

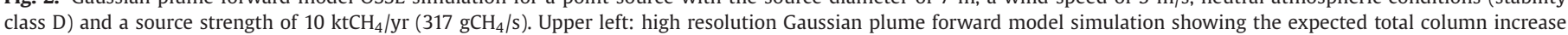

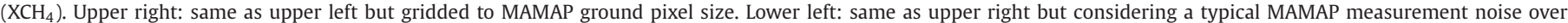
land of $\sim 0.4 \% \mathrm{XCH}_{4}(1 \sigma)$. Lower right: same as lower left, but taking a real flight track and real sampling positions into account.

"observation system simulation experiment - OSSE", was then compared to data obtained from real measurements enabling an upper limit or constraint for the observed atmospheric emissions to be estimated.

\section{Measurements and results}

\subsection{Measurements}

A series of overflights were performed on 3. June 2011 between 9:10 UTC and 12:10 UTC over the 22/4b blowout site with the AIRMETH instrumentation suite. Remote sensing measurements were performed upwind and downwind of the source at a constant aircraft altitude of $\sim 650 \mathrm{~m}$, while operating the MAMAP instrument in sunglint/sunglitter mode. This was achieved by pointing the sensor with the SM-2000 in the solar direction with a fixed zenith viewing angle (inclination) of $\sim 35^{\circ}$. Horizontal and vertical profile in-situ measurements during the overflights were performed downwind of the source at a range of distances from 22/4b (see Fig. 3) and altitudes to as low as the minimum admitted altitude of $\sim 150-200 \mathrm{~m}$, restricted in the area by air safety regulations. Previous $\mathrm{CH}_{4}$ flux estimates of the site to the water column were approximately $11 \times 10^{6} \mathrm{~L} \mathrm{CH}_{4} / \mathrm{h}$ at atmospheric pressure (corresponding to $\sim 69 \mathrm{ktCH}_{4} / \mathrm{yr}$ ) of which one third (i.e. 23 $\mathrm{ktCH}_{4} / \mathrm{yr}$ ) were emitted (in total) to the atmosphere (Deutscher Bundestag, 2010). However, these estimates have large uncertainties, which are expected to be more than one order of magnitude.

Diffusive atmospheric $\mathrm{CH}_{4}$ emissions of the site were estimated in 1994 to be between $\sim 7$ and $12 \mathrm{ktCH}_{4} / \mathrm{yr}$ (Rehder et al., 1998) and are expected to have been declining over the past 17 years. Thus, remote sensing flight patterns were optimized (pre-flight) with OSSE simulations assuming a relatively large direct source with emission rates in the order of $10 \mathrm{ktCH}_{4} / \mathrm{yr}$ and expected wind speeds of $3-5 \mathrm{~m} / \mathrm{s}$ according to the wind forecast for the area. From descent and ascent flight patterns at the beginning and the end of the remote sensing measurements, atmospheric profile information was derived from the AIMMS-20 and the Polar-5 noseboom measured data. The bubble-plume surface size diameter was estimated to be $\sim 25 \mathrm{~m}$ from pictures taken by the additionally installed on-board camera (Fig. 4) and is in good agreement with an approximately $20 \mathrm{~m}$ diameter, as estimated from ship-based visual observations reported for the same time period (Linke, 2011). 

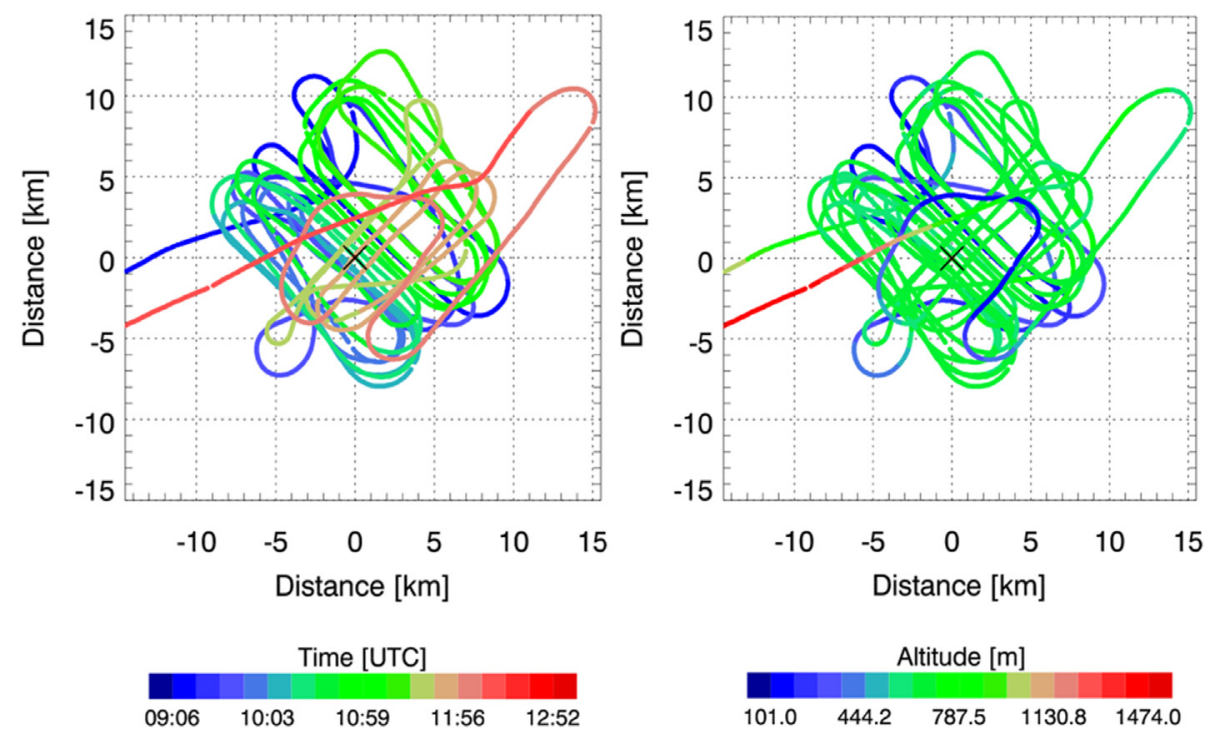

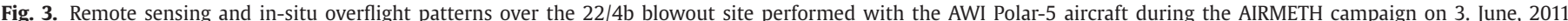

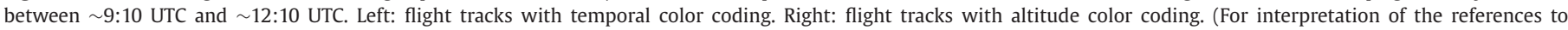
color in this figure legend, the reader is referred to the web version of this article.)

\subsection{Results from the AIMMS-20 turbulence probe and other in-situ measurements and comparison to ground based observations}

To derive wind speed and direction, the atmospheric stability class, and the boundary layer height, required for the OSSE simulations, descent and ascent in-situ profile measurements were performed with the Polar-5 aircraft close to the emission area. These measurements were compared with measurements from the nearest ground based stations. Airborne wind information was derived from AIMMS-20 turbulence probe data. The according (relative) humidity and temperature information was derived from the HTM333 Rosemount Pt100 sensors. Additionally, ground based wind and air temperature information was provided by ExxonMobil for the nearest ground stations, i.e. buoy No. 62116 (N 57.691 ${ }^{\circ}$,E $1.399^{\circ}, \sim 30 \mathrm{~km}$ in SSW direction) and the Sleipner oil-platform (N $58.37^{\circ}, \mathrm{E} 1.902^{\circ}, \sim 50 \mathrm{~km}$ in NNE direction) with the $22 / 4 \mathrm{~b}$ site located in between of both. From the combined data set, wind speed and direction as well as atmospheric stability class information has been derived and used as input for the OSSE-simulation.
Fig. 5 shows descent and ascent air temperature, potential temperature and relative humidity profiles measured on 3rd June, 2011 between 11:55 UTC - 12:10 UTC at the 22/4b site. The boundary layer height has been estimated from the vertical air temperature profile as well as from the relative humidity profile (due to the sharp increase in humidity) to be around (or below) 150-180 m above sea level.

Also shown in Fig. 5 are the surface air temperature and sea surface temperature. Surface air temperatures were measured 30$\mathrm{m}$ above sea level at the same time at the Sleipner oil platform $\sim 50 \mathrm{~km}$ north-northeast of the $22 / 4 \mathrm{~b}$ site. Sea surface temperature of $\sim 14.1{ }^{\circ} \mathrm{C}$ was measured in the Sleipner field by the ALKOR research vessel on the 3rd June 2011 (Linke et al., 2011; Peter Linke, personal communication). From the (maximum) boundary layer height of $\sim 150-\sim 180 \mathrm{~m}$ it could be concluded, that the chosen flight altitude of $\sim 650 \mathrm{~m}$ for the remote sensing measurements was sufficiently high, that the aircraft did not fly through any boundary layer atmospheric plumes originating from the measurement area. This is also supported by the fact, that no

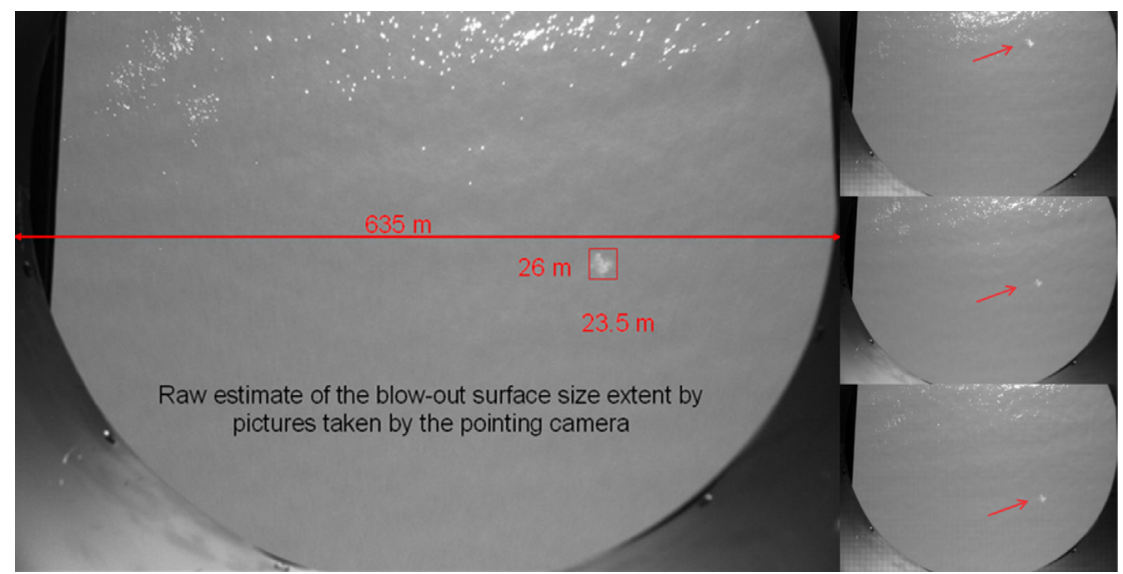

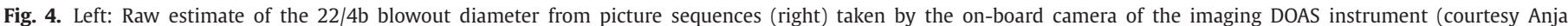

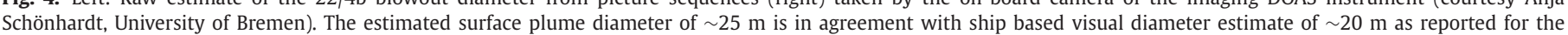
same period of time (Linke, 2011). 

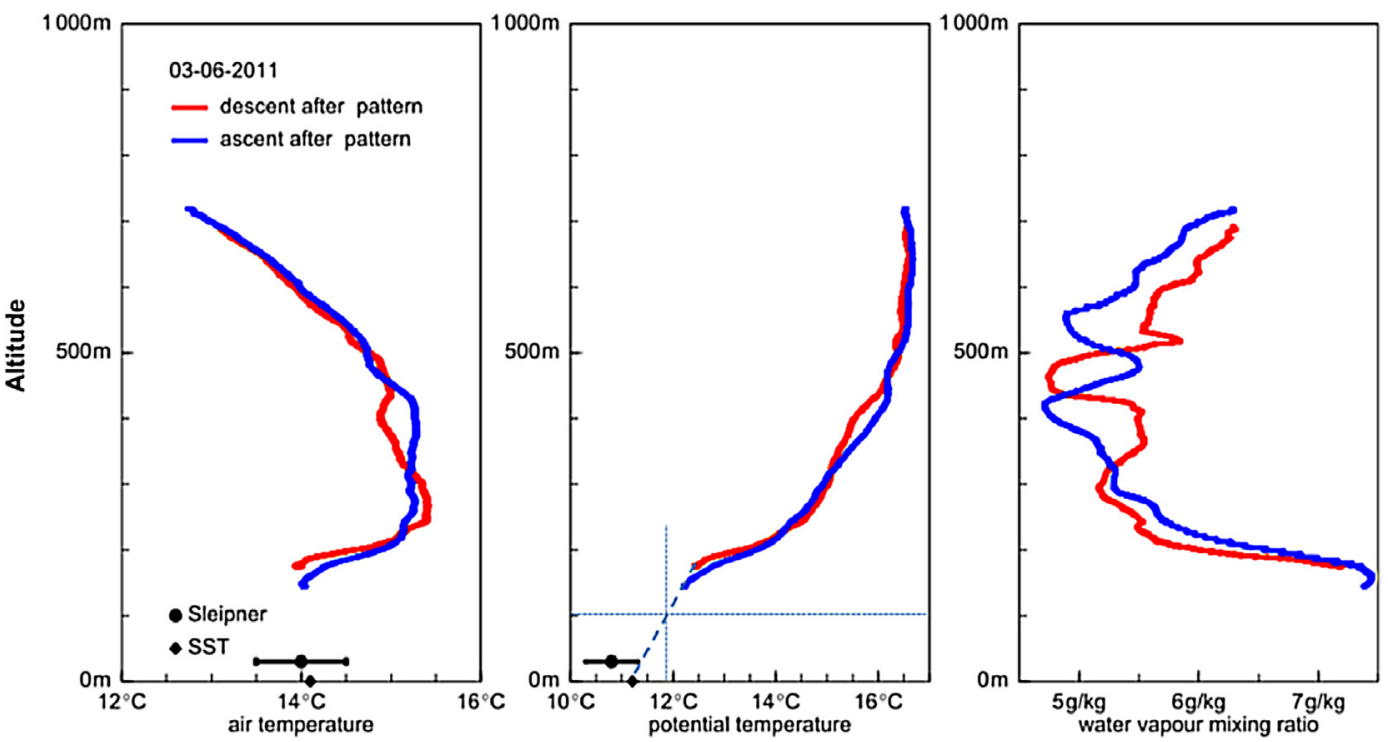

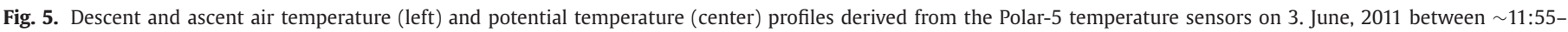

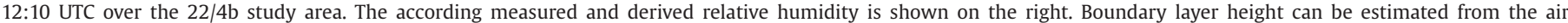

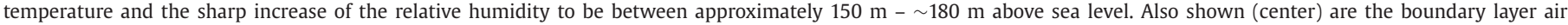

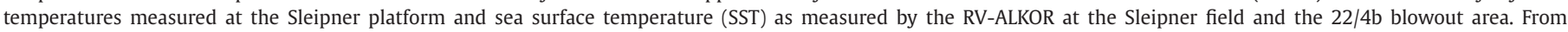

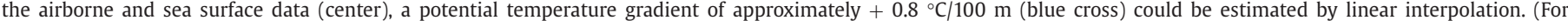
interpretation of the references to color in this figure legend, the reader is referred to the web version of this article.)

significant $\mathrm{CH}_{4}$ increase was observed above and at the top of the boundary layer by the RMT-200 $\mathrm{CH}_{4}$ in-situ gas analyzer aboard the Polar-5 in the measurement area.

Fig. 6 (left) shows descent and ascent wind velocity profiles (blue and green lines) derived from AIMMS-20 data measured between $\sim 9: 10$ and $\sim 12: 10$ UTC over the 22/4b site. Descent and ascent measurements between $\sim 700 \mathrm{~m}$ and $\sim 150 \mathrm{~m}$ were performed before and after the remote sensing measurements in the time periods between 9:10-9:40 UTC and 11:55-12:10 UTC. The triangles and dots show the wind velocity as provided from the two nearest surface stations. The reported surface wind speeds are in good agreement with the airborne data collected at the top of the boundary layer (and above) in the vicinity of the 22/4b site. A range of wind speeds during the remote sensing measurements downwind of the blowout crater (i.e. between 10:00-11:55 UTC, see Fig. 3) was therefore estimated from that combined dataset. It has been estimated that the wind speed was in the range between $\sim 4.5$ and $5.5 \mathrm{~m} / \mathrm{s}$ over the entire boundary layer (see Fig. 6 left). From Fig. 6 (right) wind directions for the corresponding time period could be obtained from the color code. Wind direction was estimated to be in the range between $200^{\circ}$ and $250^{\circ}$ in the boundary layer for the time of the downwind overflights. From the surface wind speed of $\sim 4.5-5.5 \mathrm{~m} / \mathrm{sec}$ and the potential temperature gradient of less than $\Delta \mathrm{T}+2{ }^{\circ} \mathrm{C}$ between the sea surface and the air (measured in $\sim 150 \mathrm{~m}$ altitude, see Fig. 5), the atmospheric stability class to be used for subsequent simulations can be estimated to be "D" (i.e. "Neutral") according to Hasse and Weber (1985).

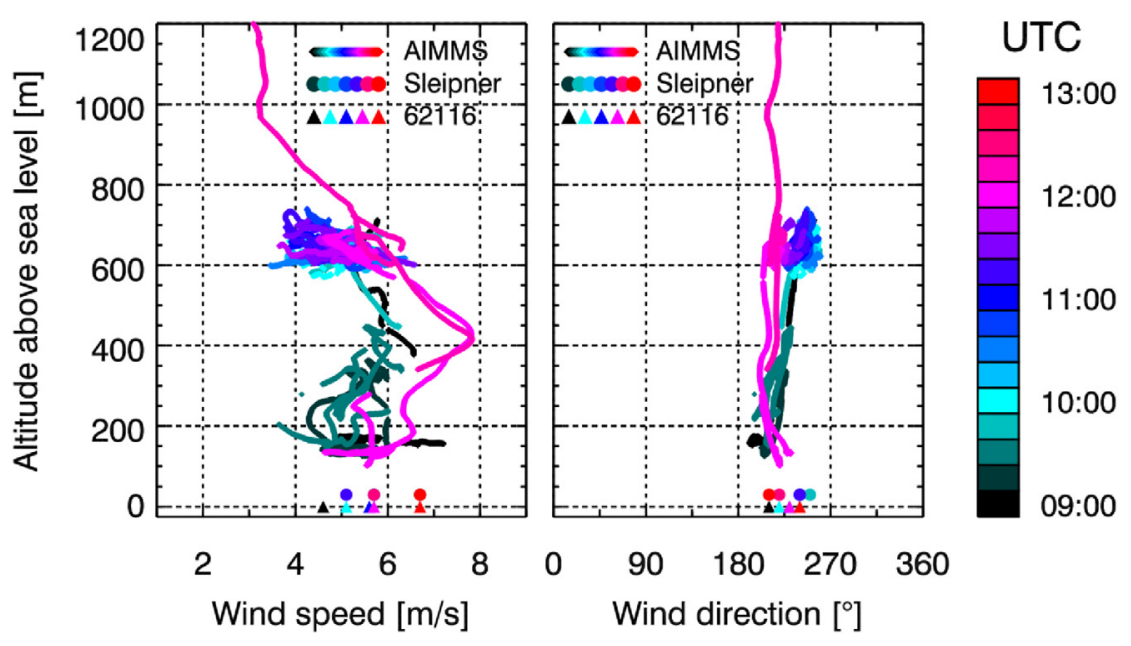

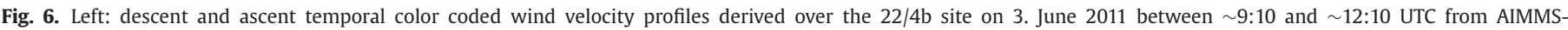

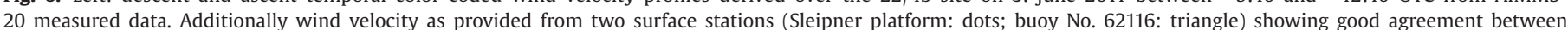

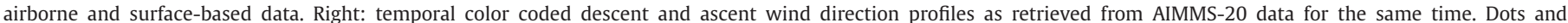

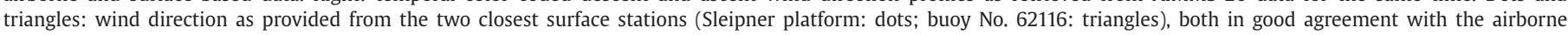
data. (For interpretation of the references to colour in this figure legend, the reader is referred to the web version of this article.) 

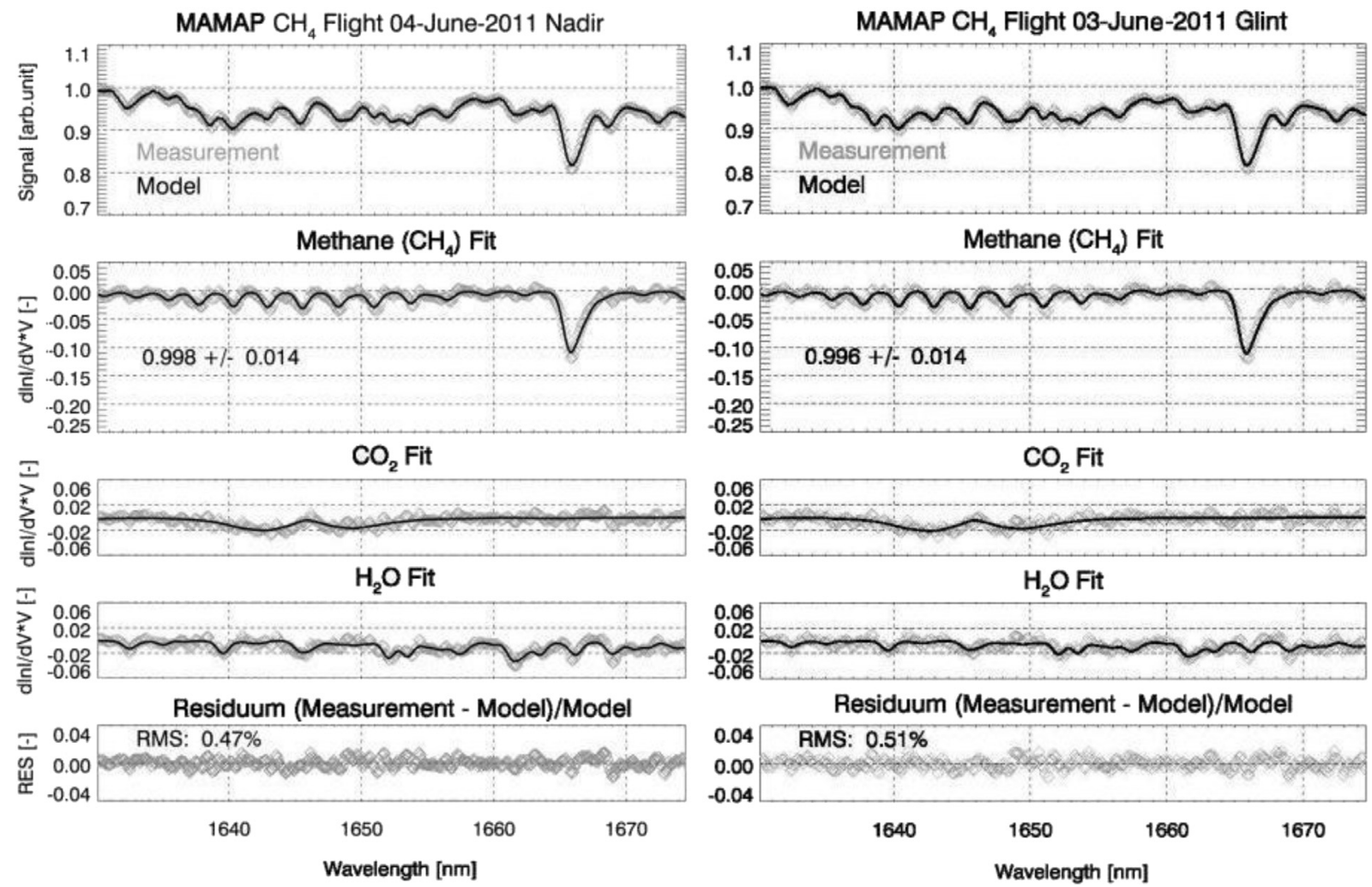

Methane $\left(\mathrm{CH}_{4}\right)$ Fit
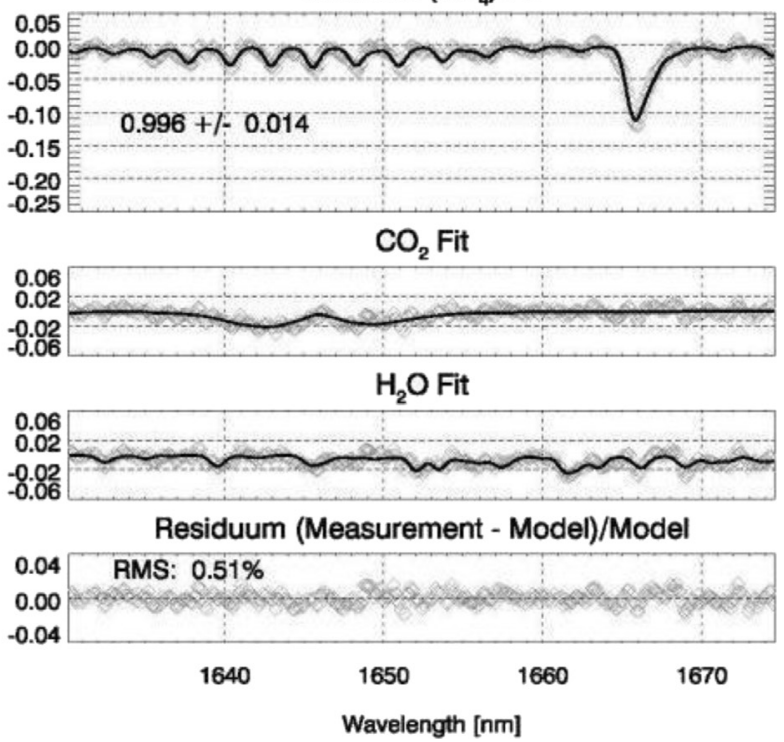

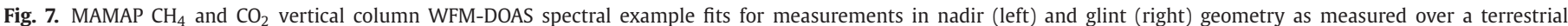

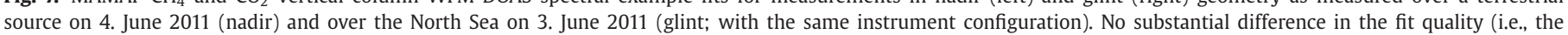
fit residua) for both measurement geometries can be observed.

\subsection{Results from remote sensing measurements}

MAMAP remote sensing data were collected between 9:40 and 11:55 UTC in the vicinity of the 22/4b site. Vertical profile scaling factors for $\mathrm{CH}_{4}$ and $\mathrm{CO}_{2}$ were retrieved from that data by the WFM-DOAS retrieval algorithm (Krings et al., 2011, 2013) using a single SCIATRAN radiative transfer model simulation for a fixed glint/glitter viewing geometry with $35^{\circ}$ nadir inclination, a solar zenith angle of $40^{\circ}, 1738 \mathrm{ppb} \mathrm{XCH}_{4}$ background concentration and a marine background aerosol profile. Sunglint/glitter surface
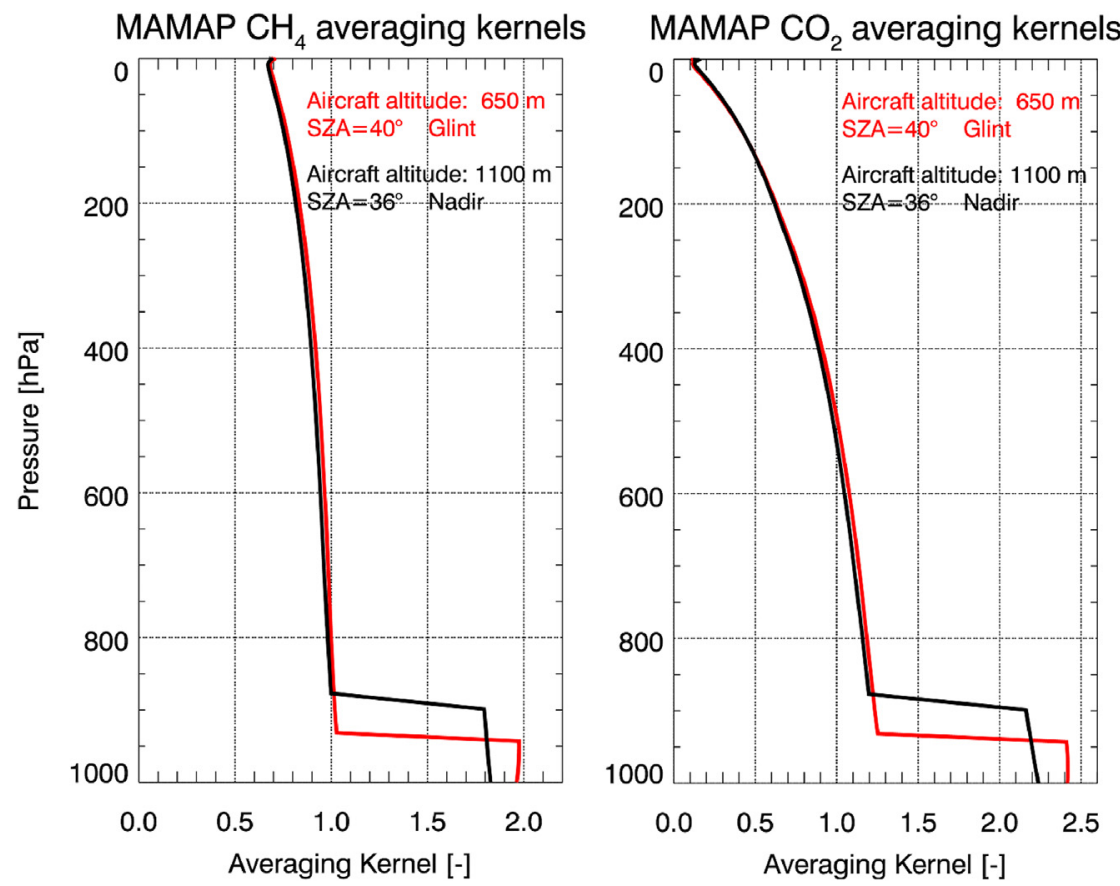

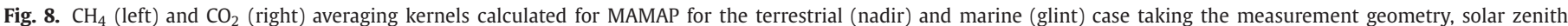

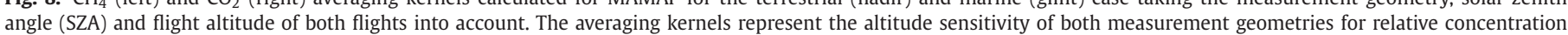
changes down to the Earth's surface. The sensitivity jump below the aircraft altitude is induced by the fact that sunlight passes the atmosphere below the aircraft twice. 

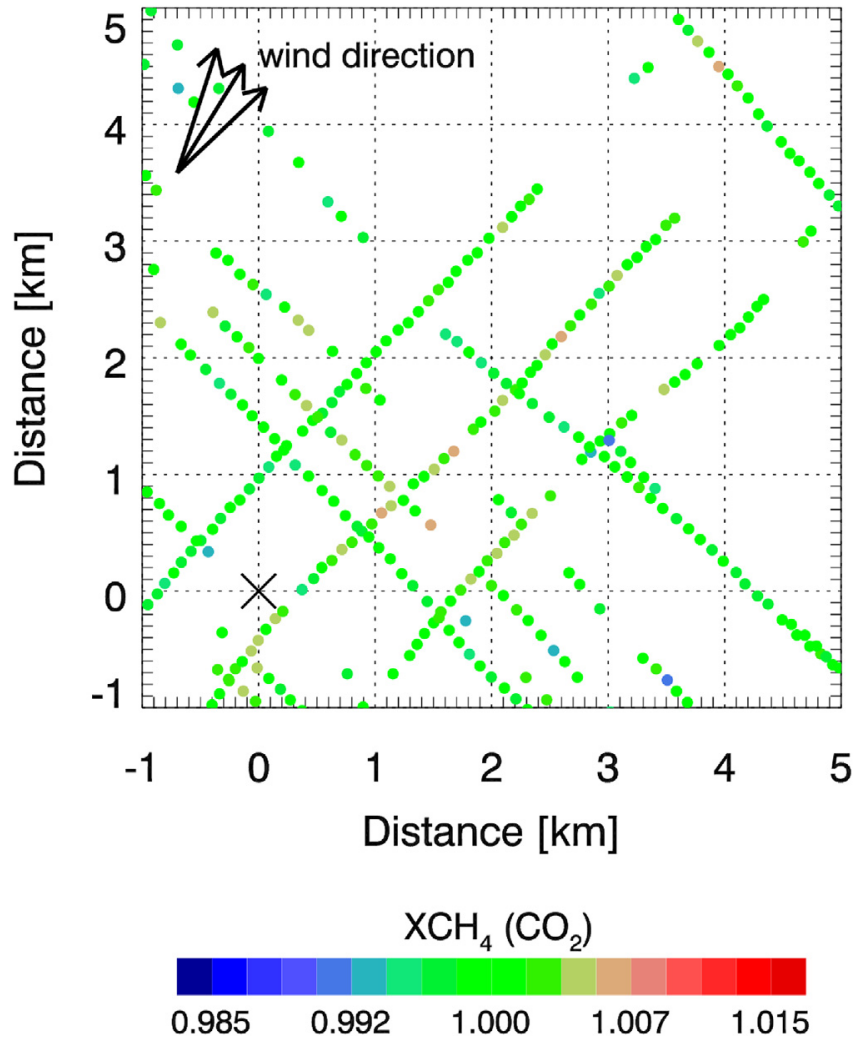

Fig. 9. Normalized $\mathrm{XCH}_{4}\left(\mathrm{CO}_{2}\right)$ map as retrieved from MAMAP sunglint/sunglitter remote sensing measurements collected over the 22/4b site on 3. June 2011 between 9:40-11:55 UTC. Measurements are line-of-sight (viewing angle) corrected and quality filtered. The black cross denotes the location of the blowout crater position, the black arrows denote the prevailing wind directions during the measurements.

spectral reflectance was calculated by SCIATRAN (incorporating the Cox and Munk Sunglint/Sunglitter model with Gaussian distribution, Cox and Munk, 1954) taking the prevailing atmospheric parameters during the overflight as well as the viewing geometry into account. The resulting mean value of the spectral radiance of $10^{13}$ [photons $\cdot \mathrm{s}^{-1} \cdot \mathrm{cm}^{-2} \cdot \mathrm{nm}^{-1} \cdot \mathrm{sr}^{-1}$ ] calculated by the RTM for the SWIR spectral channel of MAMAP were $~ 5 \%$ lower than the mean radiance calculated for the glint measurements of the entire 22/4b overflights. Considering the estimated uncertainty of the calibrated, measured radiance of about $15 \%$, this represents an excellent agreement.

The retrieved vertical profile scaling factors show a less than $3 \%$ difference with respect to the profile scaling factors derived from the atmospheric a-priori profiles used for the SCIATRAN simulation confirming the very good agreement between simulation and the measured spectra. Fig. 7, right shows MAMAP $\mathrm{CH}_{4}$ vertical column WFM-DOAS example fits and the derived column scaling factors for the spectra measured in glint/glitter viewing geometry. Nadir spectra measured one day later with the same instrument configuration (and aircraft) over a terrestrial source are shown for comparison on the left. No substantial difference in the fit quality (i.e. fit-residua) of both measurement geometries is observed, emphasizing the validity of the applied glint retrieval approach.

Fig. 8 shows for comparison the averaging kernels calculated by WFM-DOAS for $\mathrm{CH}_{4}$ (left) and $\mathrm{CO}_{2}$ (right) for the terrestrial nadir and marine glint case taking the measurement geometry and flight altitude of both flights into account. The averaging kernels are a measure for the altitude sensitivity and in this case demonstrate the sensitivity of both measurement geometries for relative con- centration changes within the boundary layer down to the Earth's surface (for more information on MAMAP averaging kernels see Krings et al., 2011).

Column-averaged $\mathrm{CH}_{4}$ dry air mole fractions (denoted as $\mathrm{XCH}_{4}\left(\mathrm{CO}_{2}\right)$ ) were calculated from the retrieved vertical profile scaling factors using $\mathrm{CO}_{2}$ as proxy, assuming that $\mathrm{CO}_{2}$ is well mixed in the atmosphere within the measurement area (Krings et al., 2011, 2013). This assumption can be applied in the absence of large $\mathrm{CO}_{2}$ emitting sources in the direct vicinity of the 22/4b crater. To justify this assumption, we performed the following estimate. We conservatively assume a $100 \mathrm{ktCO}_{2} / \mathrm{yr}$ source co-emitting with the $\mathrm{CH}_{4}$ at the same surface position. Due to the (with respect to mass) 500 times higher sensitivity of MAMAP for $\mathrm{CH}_{4}$ in comparison to $\mathrm{CO}_{2}$ (see also Gerilowski et al., 2011; Krings et al., 2011) and for an assumed $10 \mathrm{ktCH}_{4} / \mathrm{yr} 22 / 4 \mathrm{~b}$ emission, the remaining estimated error signal caused by the simultaneously emitted $\mathrm{CO}_{2}$ will be less than $2 \%$ of the retrieved $\mathrm{XCH}_{4}\left(\mathrm{CO}_{2}\right)$ total column increase. Thus an actual enhancement of $+1 \% \mathrm{XCH}_{4}\left(\mathrm{CO}_{2}\right)$ of the retrieved column relative to background could have a bias of $-0.02 \%$ with respect to the well-mixed $\mathrm{CO}_{2}$ assumption (i.e. a retrieved result of $+0.98 \% \mathrm{XCH}_{4}$ instead of $+1.00 \%$ ). Hence any biases from co-emitted $\mathrm{CO}_{2}$ not being well-mixed can be neglected for this case.

Taking into account that co-emitted $\mathrm{CO}_{2}$ from oxidation processes of dissolved $\mathrm{CH}_{4}$ in the vicinity of the bubble plume is expected to be much smaller than assumed for this calculation, the $\mathrm{CO}_{2}$ proxy approach for calculation of the column averaged dry air mole fractions is therefore valid and has been used in the subsequent calculations.

Fig. 9 shows background (regional mean) normalized $\mathrm{XCH}_{4}\left(\mathrm{CO}_{2}\right)$ column variations as retrieved from MAMAP measurements collected in sunglint/sunglitter geometry over the $22 / 4 \mathrm{~b}$ blowout site between 9:40-11:55 UTC. Measurement positions are line-of-sight (viewing angle) corrected and quality filtered. Quality filtering was performed for inclination variations, detector filling and fit quality (for more information on quality filtering see Krings et al., 2011, 2013). The $\mathrm{XCH}_{4}\left(\mathrm{CO}_{2}\right)$ column precision (standard variation) for the filtered data was estimated to be $\sim 0.25 \%(1 \sigma)$, i.e., equal to a total column $\mathrm{CH}_{4}$ precision (below the aircraft) of $\sim 37 \mathrm{ppm}^{*} \mathrm{~m}$ (referred to a $1013 \mathrm{hPa}$ normalized total atmospheric thickness of about $8580 \mathrm{~m}$ and a $\mathrm{XCH}_{4}$ background concentration of $1738 \mathrm{ppb})$. The black cross denotes the location of the blowout crater. The measurements show no significant total column increase in contrast to a total column increase, which would be expected for a $10 \mathrm{ktCH}_{4} / \mathrm{yr}$ source as used for the pre-flight simulations.

\section{Upper-limit estimate of direct atmospheric 22/4b methane emissions obtained by comparison of remote sensing results with OSSE simulations}

To constrain the direct 22/4b emissions caused by ebullition/bubbling, a number of Gaussian plume OSSE simulations (see Section 2.2.2) for different source strengths and wind directions have been performed taking the MAMAP flight track into account. The results were then compared to results obtained from 22/4b MAMAP measured data.

The OSSE forward model simulations were performed for an average wind speed of $5.5 \mathrm{~m} / \mathrm{s}$ (i.e upper range of observed lower boundary layer wind speeds, see Fig. 6 - left), the prevailing wind directions (between $\sim 200^{\circ}$ and $245^{\circ}$, estimated from Fig. 6 - right) and the atmospheric stability class "D" (neutral) as estimated in Section 3.2. The simulated source emission was varied from zero to $10 \mathrm{ktCH}_{4} / \mathrm{yr}$ in steps of $2.5 \mathrm{ktCH}_{4} / \mathrm{yr}$. For comparison, a simulation of a larger $15 \mathrm{ktCH}_{4} / \mathrm{yr}$ source as well as simulations for the more stable atmospheric stability class "E" for 

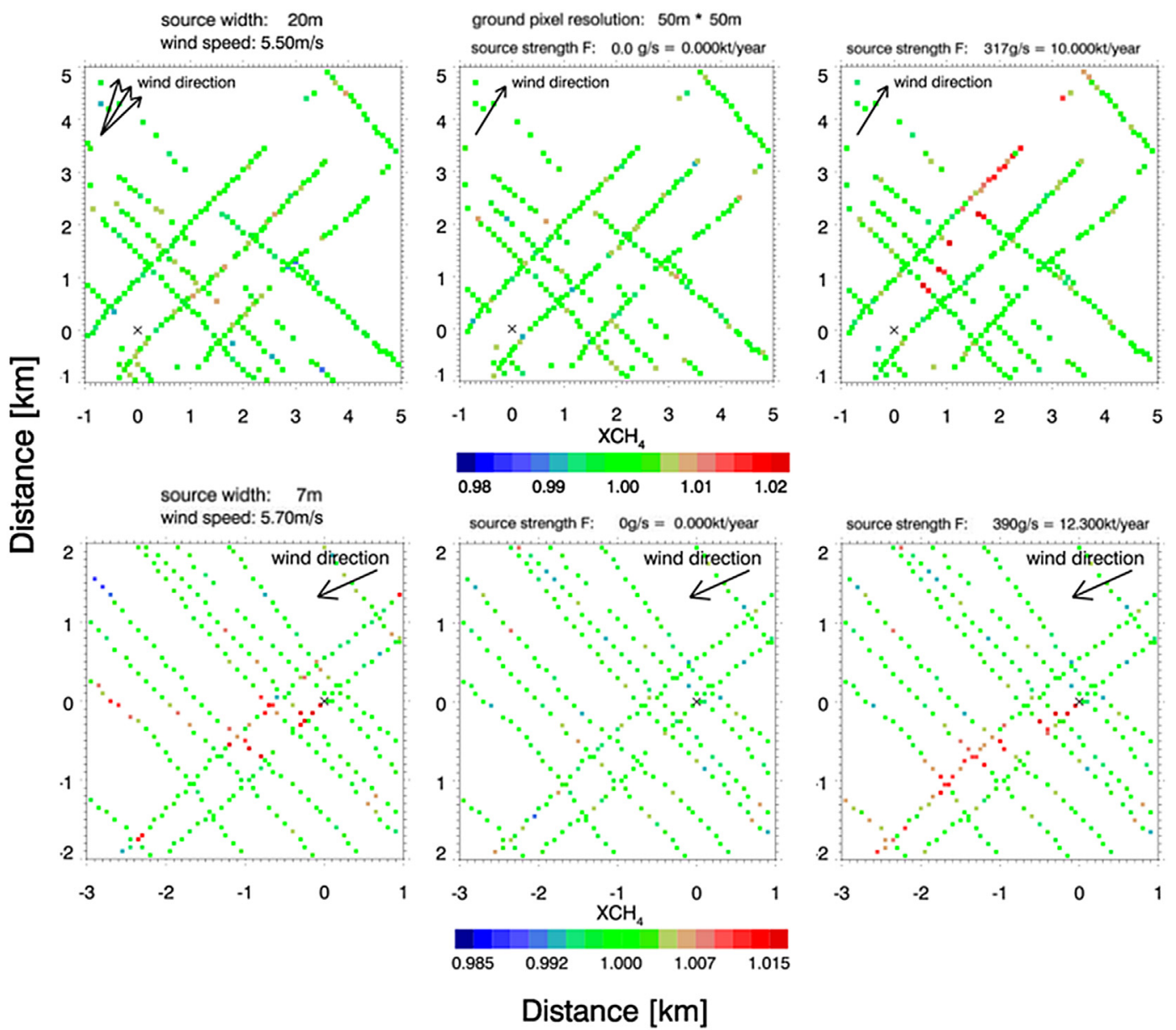

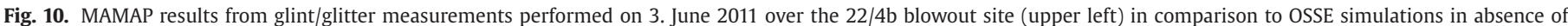

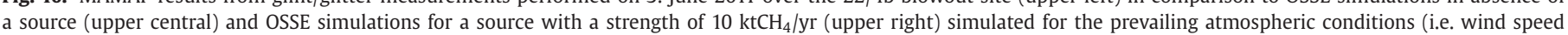

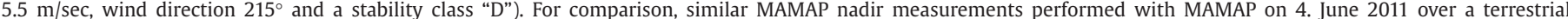

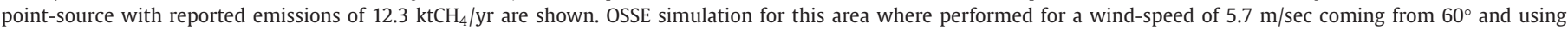
stability class "C" (for more information see also Krings et al., 2013).

different wind directions were also performed and are shown in the Supplementary material. The ground pixel size used for the simulation was set to $50 \mathrm{~m} \times 50 \mathrm{~m}$ according to the similar proximate ground scene size of MAMAP. A noise of $0.25 \%(1 \sigma)$ as estimated for the MAMAP $\mathrm{XCH}_{4}\left(\mathrm{CO}_{2}\right)$ column precision from the filtered data was added to the simulated (synthetic) data. Simulations were performed only for measurement positions, where data were acquired with the instrument on the Polar-5 flight track.

Fig. 10 shows gridded MAMAP results from the real glint/glitter measurements performed over the 22/4b blowout site (upper left) in comparison to OSSE simulations in the absence of any source (upper central) and OSSE simulations for a source with a source strength of $10 \mathrm{ktCH}_{4} / \mathrm{yr}$ (upper right) simulated for the prevailing atmospheric conditions (i.e. wind speed of $5.5 \mathrm{~m} / \mathrm{sec}$, wind direction of $215^{\circ}$, stability class "D"). The measurements show no significant total column increase in comparison to a total column increase as would be expected for a point source with direct atmospheric emissions of $\sim 10 \mathrm{ktCH}_{4} / \mathrm{yr}$ for this flight pattern and weather conditions.

For comparison, similar MAMAP nadir measurements performed one day later over a terrestrial point-source with reported emissions of $12.3 \mathrm{ktCH}_{4} / \mathrm{yr}$ are also shown. These measurements were performed with MAMAP in nadir geometry over the
Bockraden shaft of the Ibbenbüren coal mine located in northern Germany at a remote sensing measurement altitude of $1100 \mathrm{~m}$. OSSE simulations for this area where performed for a wind-speed of $5.7 \mathrm{~m} / \mathrm{sec}$, wind direction of $60^{\circ}$ and stability class "C" (for more information and a complete analysis of the Ibbenbüren data set see also Krings et al., 2013). In that case, measurement results agree well with the OSSE simulations for a source of same magnitude.

Based on these simulations and comparison to real measured data, it is concluded, that direct 22/4b blowout emissions caused by bubbling/ebullition were very probably well below 10 $\mathrm{ktCH}_{4} / \mathrm{yr}$. To emphasize this conclusion, additional OSSE simulations with different source magnitudes and wind directions were performed.

Fig. 11 shows OSSE simulations for the 22/4b blowout site with the same atmospheric parameters as shown in Fig. 10 (upper right) but for source strengths ranging from 2.5 to $10 \mathrm{ktCH}_{4} / \mathrm{yr}$. To better illustrate the extent of the plume, additional contour lines were added to the plot. Figure S.1.2 to S.1.5 (Supplementary material) show additional simulations for different wind directions ranging from $200^{\circ}$ to $245^{\circ}$ (in $15^{\circ}$ steps) covering the range of observed boundary layer wind directions in the area (see Section 3.2). Furthermore, a stronger source of $15 \mathrm{ktCH}_{4} / \mathrm{yr}$ (Fig. S.1.1) was also simulated for comparison. 


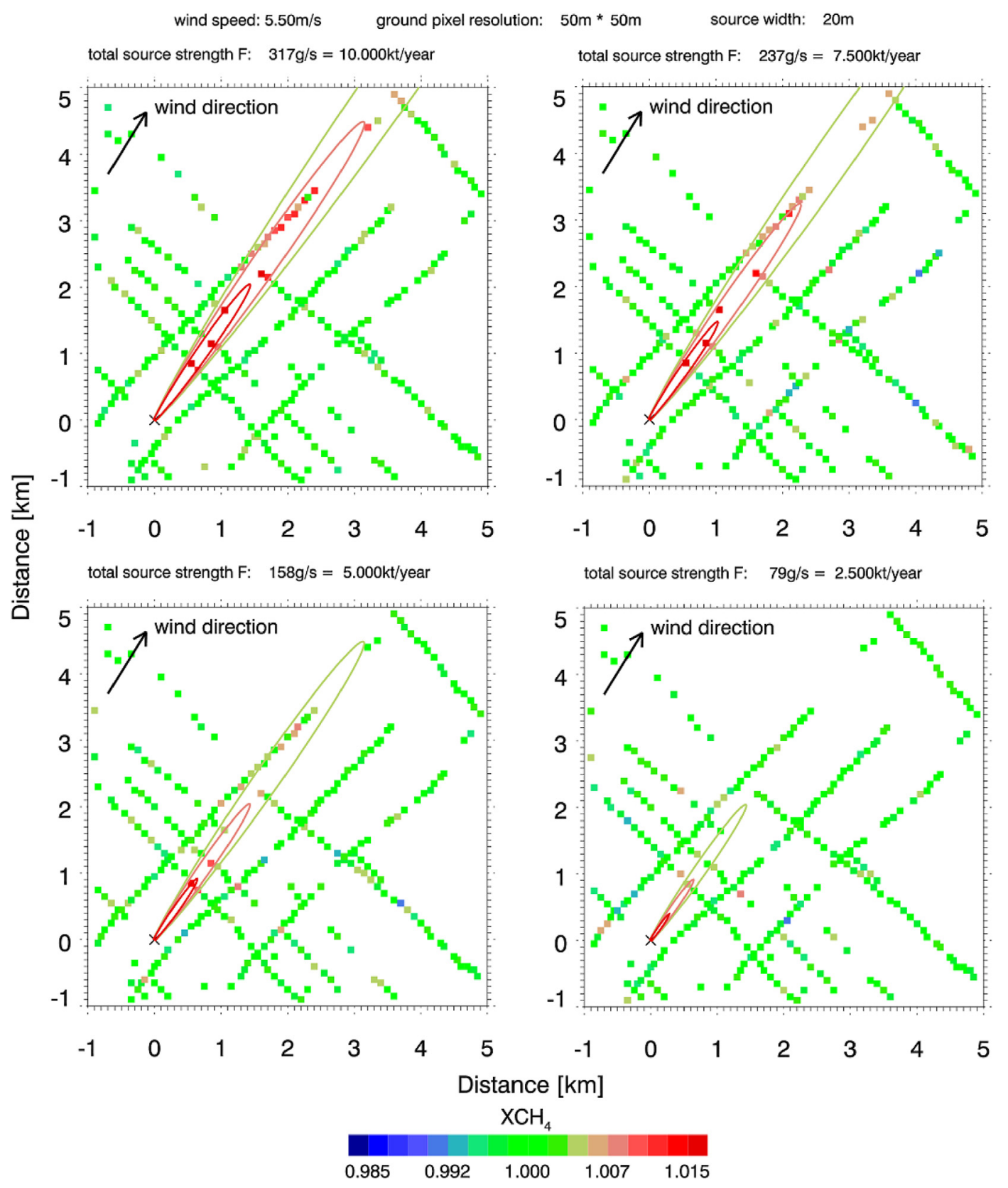

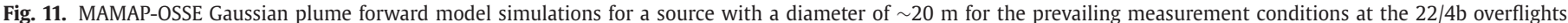

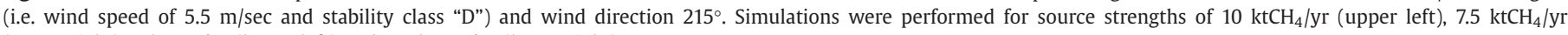
(upper right), $5 \mathrm{ktCH}_{4} / \mathrm{yr}$ (lower left) and $2.5 \mathrm{ktCH}_{4} / \mathrm{yr}$ (lower right).

These simulations supported the conclusion that the direct 22/4b blowout emissions by ebullition during the overflight most probably were below $10 \mathrm{ktCH}_{4} / \mathrm{yr}$, likely were below $7.5 \mathrm{ktCH}_{4} / \mathrm{yr}$ and potentially were even below $5 \mathrm{ktCH}_{4} / \mathrm{yr}$. Emissions of a 2.5 $\mathrm{ktCH}_{4} / \mathrm{yr}$ source as simulated with the OSSE for the flown flight track were most probably not detectable for the given wind speed, and stability and would require a much denser flight pattern near the source to be visible in the measured data. These findings are in line with ship based observations, where even smaller emission rates were estimated based on atmospheric in-situ measurements in combination with Gaussian plume modeling (Leifer et al., this issue) or by surface video observations combined with chemical analysis of the bubble $\mathrm{CH}_{4}$ content at the sea surface (Schneider von Deimling et al., this issue).

\section{Summary and conclusions}

On 3rd June 2011 remote sensing and in-situ overflights were made over the North Sea 22/4b blowout site with the AWI-Polar-5 aircraft, which was equipped with the MAMAP remote sensing instrument, an RMT-200 fast methane in-situ analyzer as well as the Polar-5 basic instrumentation suite including 2 turbulence probes and different temperature, humidity and pressure sensors. The MAMAP remote sensing data showed no detectable increase in the derived $\mathrm{XCH}_{4}$ (with respect to the atmospheric background) exceeding the instruments measurement precision. MAMAP OSSE forward model simulations were performed for the prevailing atmospheric conditions (derived from the atmospheric measurements) assuming a local source with different source strengths. These 
simulations represent the expected remote sensing results as would be measured with the instrument for the according emissions. The OSSE simulation for a source strength of $10 \mathrm{ktCH}_{4} / \mathrm{yr}$ revealed, that this emission magnitude should have been detectable in the collected MAMAP data. This conclusion is further supported by terrestrial MAMAP measurements in nadir geometry over a source (with known and reported emissions of similar magnitude) and comparisons to the according OSSE simulation (see Fig. 10). Consequently, it can be concluded, that the direct 22/4b blowout emissions caused by bubble plumes are very probably well below $10 \mathrm{ktCH}_{4} / \mathrm{yr}$ for the time of the overflights. Comparisons of OSSE simulations for four source strengths (i.e. 2.5, 5, 7.5, and 10 $\mathrm{ktCH} 4 / \mathrm{yr}$ ), different wind directions as well as two atmospheric stability classes (see Fig. 11 and Supplementary material) with MAMAP data further supported the conclusions, that the direct 22/4b blowout emissions by ebullition during the overflight likely were below $7.5 \mathrm{ktCH}_{4} / \mathrm{yr}$ and potentially even below $5 \mathrm{ktCH}_{4} / \mathrm{yr}$. OSSE simulations for a $2.5 \mathrm{ktCH}_{4} / \mathrm{yr}$ source and prevailing atmospheric conditions indicate, that the $\mathrm{XCH}_{4}$ total column increases produced by that source most probably would not have been detectable by the instrument with the actually flown flight pattern and distance to the source and therefore would not be recognized in the measured data.

In conclusion, the upper limit of the direct atmospheric $\mathrm{CH}_{4}$ flux from the main bubble plume is estimated to be below 10 $\mathrm{ktCH}_{4} / \mathrm{yr}$. The results reported here are determined from comparisons of OSSE simulations with MAMAP measurements, obtained from a single flight, where flight patterns were optimized for large source magnitudes in the order of $10 \mathrm{ktCH}_{4} / \mathrm{yr}$. Additional flights optimized for smaller source strengths with denser flight lines closer to the source are required to improve from an upper limit to estimates of the smaller direct surface fluxes of $\mathrm{CH}_{4}$ form this blowout.

The new technologies and approaches described in this paper can be used for estimating emissions from other offshore and onshore accidental large scale natural gas releases. For instance, the emission rates estimated for March to May during the Elgin accident (Mobbs et al., 2012) range from $\sim 1 \mathrm{kgCH}_{4} / \mathrm{s}(\sim 31$ $\left.\mathrm{ktCH}_{4} / \mathrm{yr}\right)$ to $\sim 0.5 \mathrm{kgCH}_{4} / \mathrm{s}\left(\sim 15.5 \mathrm{ktCH}_{4} / \mathrm{yr}\right)$ and were therefore well in the application range of the methods described in this paper. Unlike classical in-situ methods used up to date, passive remote sensing methodologies do not require low level flight operation and hence can be applied without safety concerns directly above exclusion zones typically established for safety reasons during such accidents. The only drawback of these methods with respect to classical in-situ methods is the requirement for clear sky conditions, and solar zenith angles of below of approximately $80^{\circ}$ during the measurements.

\section{Acknowledgments}

AIRMETH Polar-5 flights and ground operations were supported and financed in different ways by the Alfred Wegener Institute for Polar and Marine Research (AWI), Germany, the Helmholtz Association, Germany, Helmholtz Centre Potsdam - German Research Centre for Geosciences (GFZ), Germany and the University and State of Bremen, Germany.

AIRMETH 22/4b MAMAP data retrieval was financed in different ways by BRI, United States, and the University and State of Bremen, Germany.

AIRMETH Polar-5 auxiliary data was provided by Martin Gehrmann, Alfred Wegener Institute for Polar and Marine Research (AWI), Bremerhaven, Germany.

Ground based wind and temperature data were provided by J.P. Smith, ExxonMobil Corporation.

Imaging DOAS instrument on board camera data have been pro- vided by Anja Schönhardt, IUP, University of Bremen, Germany.

The solar spectrum used for analysis of the remote sensing data

has been obtained from NSO/Kitt Peak (http://solarnews.nso.edu) and was produced cooperatively by NSF/NOAO, NASA/GSFC and NOAA/SEL.

\section{Appendix A. Supplementary data}

Supplementary material related to this article can be found at http://dx.doi.org/10.1016/j.marpetgeo.2015.07.011.

\section{References}

Bradley, E.S., Leifer, I., Roberts, D.A., Dennison, P.E., Washburn, L., 2011. Detection of marine methane emissions with AVIRIS band ratios. Geophys. Res. Lett. 38 L10702. http://dx.doi.org/10.1029/2011GL046729.

Butz, A., Guerlet, S., Hasekamp, O.P., Kuze, A., Suto, H., 2013. Using oceanglint scattered sunlight as a diagnostic tool for satellite remote sensing of greenhouse gases. Atmos. Meas. Tech. 6, 2509-2520. http://dx.doi.org/10.5194/ amt-6-2509-2013. www.atmos-meas-tech.net/6/2509/2013/.

Cox, C., Munk, W., 1954. Measurement of the roughness of the sea surface from photographs of the suns glitter. J. Opt. Soc. Am. 44, 838-850.

Cremer, M., 2008. Kalibrierung der Turbulenzmesssonde der Polar 5 Messwerk, Dok.-Nr. mW-AWI-P5-2008-06, Datum: 21.07.2008A.

Deutscher Bundestag - 17 Wahlperiode, 2010. Erdgas-Blowout vor der Küste Schottlands Drucksache 17/4342 http://dipbt.bundestag.de/dip21/btd/17/043/ 1704342.pdf last download 12/19/2013.

Gerilowski, K., Tretner, A., Kring, s T., Buchwitz, M., Bertagnolio, P.P., Belemezov, F. Erzinger, J., Burrows, J.P., Bovensmann, H., 2011. MAMAP - a new spectrometer system for column-averaged methane and carbon dioxide observations from aircraft: instrument description and performance analysis. Atmos. Meas. Tech. 4, 215-243. http://dx.doi.org/10.5194/amt-4-215-2011. www.atmos-meas-tech. net $/ 4 / 215 / 2011 /$.

Hasse, L., Weber, H., 1985. On the conversion of Pasquill categories for use over Sea. Bound. Layer Meteorol. 31, 177-185.

Krings, T., Gerilowski, K., Buchwitz, M., Reuter, M., Tretner, A., Erzinger, J., Heinze, D. Pflüger, U., Burrows, J.P., Bovensmann, H., 2011. MAMAP - a new spectrometer system for column-averaged methane and carbon dioxide observations from aircraft: retrieval algorithm and first inversions for point source emission rates. Atmos. Meas. Tech. 4, 1735-1758. http://dx.doi.org/10.5194/amt-4-1735-2011. www.atmos-meas-tech.net/4/1735/2011/

Krings, T., Gerilowski, K., Buchwitz, M., Hartmann, J., Sachs, T., Erzinger, J., Burrows, J.P., Bovensmann, H., 2013. Quantification of methane emission rates from coal mine ventilation shafts using airborne remote sensing data. Atmos. Meas. Tech. 6, 151-166. http://dx.doi.org/10.5194/amt-6-151-2013. www. atmos-meas-tech.net/6/151/2013/.

Larsen, N.F., Stamnes, K., 2006. Methane detection from space: use of sunglint. Opt Eng. 45 (1), 016202. http://dx.doi.org/10.1117/1.2150835, SPIE.

Leifer, I., Judd, A., 2015. The UK22/4b blowout 20 years on: investigations of continuing methane emissions from sub-seabed to the atmosphere in a North Sea context. J. Mar. Pet. Geol. in this issue.

Leifer, I., Solomon, E., Schneider von Deimling, J., Coffin, R., Rehder, G., Linke, P., 2015. The fate of bubbles in a large, intense bubble plume for stratified and unstratified water: numerical simulations of $22 / 4 \mathrm{~b}$ expedition field data. J. Mar. Pet. Geol. in this issue.

Linke, P. (Ed.), 2011. RV ALKOR Fahrtbericht/Cruise Report AL374, Berichte aus dem Leibniz-Institut für Meereswissenschaften an der Christian-Albrechts-Universität zu Kiel, Nr. 51, ISSN Nr., pp. 1614-6298.

Martin, D.O., 1976. The change of concentration standard deviations with distance. J. Air Pollut. Control Assoc. 26, 145-147. http://dx.doi.org/10.1080/00022470.1976. 10470238.

Mobbs, S., Bauguitte, S., Wellpott, A., Burton, R., Lee, J., Lewis, A., Punjabi, S., 2012. Monitoring of the Elgin Rig Leak Using the FAAM Atmospheric Research Aircraft Final report. National Centre for Atmospheric Science, School of Earth and Environment, University of Leeds, Leeds LS2 9JT, UK December 2012 http://www.ncas.ac.uk/index.php/en/documents/doc_download/ 299-ncas-2-evidence-10-finalreport

O'Keefe, A., Scherer, J.J., Paul, J.B., 1999. Los Gatos research, CW integrated cavity output spectroscopy. Chem. Phys. Lett. 307, 343-349.

Peltola, O., Mammarella, I., Haapanala, S., Burba, G., Vesala, T., 2013. Field intercomparison of four methane gas analyzers suitable for eddy covariance flux measurements. Biogeosciences 10, 3749-3765. http://dx.doi.org/10.5194/ bg-10-3749-2013. www.biogeosciences.net/10/3749/2013/.

Rehder, G., Keir, R.S., Suess, E., Pohlmann, T., 1998. The multiple sources and patterns of methane in North sea waters. Aquat. Geochem. 4, 403-427.

Roberts, D.A., Bradley, E.S., Cheung, R., Leifer, I., Dennison, P.E., Margolis, J.S., 2010 Mapping methane emissions from a marine geological seep source using imaging spectrometry. Remote Sens. Environ. 114, 592-606. http://dx.doi.org/10.1016/ j.rse.2009.10.015.

Rozanov, V.V., Rozanov, A.V., Kokhanovsky, A.A., Burrows, J.P., 2013. Radiative transfer through terrestrial atmosphere and ocean: software package SCIATRAN. J. Quant. Spectrosc. Radiat. Transf. http://dx.doi.org/10.1016/j.jqsrt.2013.07.004, ISSN 0022-4073. 
Schneider von Deimling, J., Brockhoff, J., Greinert, J., 2007. Flare imaging with multibeam systems: data processing for bubble detection at seeps. Geochem. Geophys. Geosys. http://dx.doi.org/10.1029/2007GC001577. http://onlinelibrary. wiley.com/doi/10.1029/2007GC001577/abstract.

Schneider von Deimling, J., Linke, P., Schmidt, M., Rehder, G., 2015. A mega methane gas plume with spiral vortex motion - insights about the 1 abandoned blowout site in the North Sea since 2005. J. Mar. Pet. Geol. in this issue.

Schneising, O., Burrows, J.P., Dickerson, R.R., Buchwitz, M., Reuter, M., Bovensmann, H., 2014. Remote sensing of fugitive methane emissions from oil and gas production in North American tight geologic formations. Earth's Future 2. http://dx.doi.org/10.1002/2014EF000265.

Schönhardt, A., Altube, P., Gerilowski, K., Krautwurst, S., Hartmann, J., Meier, A.C., Richter, A., Burrows, J.P., 2014. A wide field-of-view imaging DOAS in- strument for continuous trace gas mapping from aircraft. Atmos. Meas. Tech. Discuss. 7, 3591-3644. http://dx.doi.org/10.5194/amtd-7-3591-2014. www. atmos-meas-tech-discuss.net/7/3591/2014/.

Thorpe, A.K., Frankenberg, C., Roberts, D.A., 2014. Retrieval techniques for airborne imaging of methane concentrations using high spatial and moderate spectral resolution: application to AVIRIS. Atmos. Meas. Tech. 7, 491-506. http://dx.doi. org/10.5194/amt-7-491-2014. www.atmos-meas-tech.net/7/491/2014/.

Tratt, D.M., Buckland, K.N., Hall, J.L., Johnson, P.D., Keim, E.R., Leifer, I., Westberg, K., Young, S., 2014. Airborne visualization and quantification of discrete methane sources in the environment. Remote Sens. Environ. 154, 74-88. 